\title{
Medicinal Product Identifier
}

National Cancer Institute

\section{Source}

National Cancer Institute. Medicinal Product Identifier. NCI Thesaurus. Code C142606.

A worldwide unique identifier allocated to a medicinal product that is supplementary to any existing identifier approved by a regulatory authority in the country of authorization. 